\title{
Immunotherapy Using Dendritic Cells against Multiple Myeloma: How to Improve?
}

\author{
Thanh-Nhan Nguyen-Pham, ${ }^{1,2}$ Yoon-Kyung Lee, ${ }^{1,3}$ Hyeoung-Joon Kim, ${ }^{2}$ and Je-Jung Lee, ${ }^{1,3}$ \\ ${ }^{1}$ Research Center for Cancer Immunotherapy, Chonnam National University Hwasun Hospital, Hwasun, \\ Jeollanamdo 519-763, Republic of Korea \\ 2 Department of Hematology-Oncology, Chonnam National University Hwasun Hospital, 160 Seoyangro, \\ Hwasun, Jeollanamdo 519-763, Republic of Korea \\ ${ }^{3}$ Vaxcell-Bio Therapeutics, Hwasun, Jeollanamdo 519-763, Republic of Korea
}

Correspondence should be addressed to Je-Jung Lee, drjejung@chonnam.ac.kr

Received 4 November 2011; Accepted 2 January 2012

Academic Editor: Qing Yi

Copyright (c) 2012 Thanh-Nhan Nguyen-Pham et al. This is an open access article distributed under the Creative Commons Attribution License, which permits unrestricted use, distribution, and reproduction in any medium, provided the original work is properly cited.

\begin{abstract}
Multiple myeloma (MM) is a good target disease in which one can apply cellular immunotherapy, which is based on the graftversus-myeloma effect. This role of immune effector cells provides the framework for the development of immune-based therapeutic options that use antigen-presenting cells (APCs) with increased potency, such as dendritic cells (DCs), in MM. Current isolated idiotype (Id), myeloma cell lysates, myeloma dying cells, DC-myeloma hybrids, or DC transfected with tumor-derived RNA has been used for immunotherapy with DCs. Immunological inhibitory cytokines, such as TGF- $\beta$, IL-10, IL-6 and VEGF, which are produced from myeloma cells, can modulate antitumor host immune response, including the abrogation of DC function, by constitutive activation of STAT3. Therefore, even the immune responses have been observed in clinical trials, the clinical response was rarely improved following DC vaccinations in MM patients. We are going to discuss how to improve the efficacy of DC vaccination in MM.
\end{abstract}

\section{Introduction}

Multiple myeloma (MM) is a clonal B cell malignant disease that is characterized by the proliferation of plasma cells in the bone marrow (BM) in association with monoclonal protein in the serum and/or urine, immune paresis, skeletal destruction, renal dysfunction, anemia, hypercalcemia and lytic bone diseases $[1,2]$. Although the introduction of conventional chemotherapy, high-dose therapy with hematopoietic stem cell transplantation (HSCT), and the development of novel molecular target agents has resulted in a marked improvement in overall survival, the disease still remains incurable $[3,4]$. Alternative approaches are clearly needed to prolong the disease-free survival, as well as the overall survival of patients with MM. To prolong the survival of patients with MM who are undergoing allogeneic HSCT, donor lymphocyte infusion can be used successfully as a salvage therapy, which is based on the graft-versus-myeloma effect in some cases of MM that relapse after allogeneic HSCT [5-7]. This role of immune effector cells provides the framework for the development of immune-based therapeutic options that use antigen-presenting cells (APCs) with increased potency, such as dendritic cells (DCs), in MM [6, 7].

DCs are the most potent APCs for initiating cellular immune responses through the stimulation of naive $\mathrm{T}$ cells. Immature DCs are good at antigen uptake and processing, but for a stimulatory T-cell response they must mature to become fully activated DCs, which express high levels of cell surface-related major histocompatibility complex- (MHC-) antigen and costimulatory molecules. Because of their ability to stimulate $\mathrm{T}$ cells, DCs act as a link in antitumor immune responses between innate immunity and adaptive immunity [8]. These DCs play a central role in various immunotherapy protocols by generation of cytotoxic T lymphocytes (CTLs) [9]. DC-based vaccines have become the most attractive tool for cancer immunotherapy and have been used in 
the treatment of more than 20 malignancies, most commonly melanoma, renal cell carcinoma, prostate cancer, and colorectal carcinoma $[10,11]$. In MM, cellular immunotherapy using DCs is emerging as a useful immunotherapeutic modality to treat MM [10]. Since tumor antigen-loaded DCs are expected to be able to stimulate tumor-specific CTLs and to overcome $\mathrm{T}$ cell tolerance in tumor patients, the development of DC vaccines that can consistently eliminate minimal residual neoplastic disease remains an important goal in the field of tumor immunology [12].

\section{Current DC Therapy in MM}

$\mathrm{MM}$ is believed to induce immunoparesis that interferes with DC function, which diminishes the effective antitumor immune responses in these patients. Usually, ex vivo DCs are generated from circulating blood precursors (i.e., monocytes) or bone marrow progenitor cells and are educated with tumor antigens prior to vaccination to patients. Ex vivo generated DCs can be loaded with myeloma-associated antigens as vaccines for patients with MM. The use of immature DCs or mature DCs, the way to induce DC maturation, types of tumor antigens, the techniques to load tumor antigens to DCs, routes of administration, and dosing schedules are being investigated [13].

2.1. Idiotype-Pulsed DCs. Immunoglobulin Idiotype (Id) is a tumor-specific antigen can be defined that each B cell tumor clone produces. Id can be readily isolated from the plasma of MM patients [14]. The Id protein has been used for immunotherapy both in vitro and in vivo in $\mathrm{MM}$ and has demonstrated a successful response in follicular lymphoma and a unique expression of Id on the malignant $\mathrm{B}$ cell clone $[15,16]$. Id vaccination could induce both antibody and Id-specific $\mathrm{T}$ cells including $\mathrm{CD} 4^{+} \mathrm{T}$ cell and $\mathrm{CD} 8^{+} \mathrm{T}$ cell response by the presentation of Id protein on MHC class I and II of professional APCs, such as DCs. Id-specific CTL lines could be generated that killed autologous primary myeloma cells in vitro, and killing activity was induced by only MHC class I restricted [17], while in the other report both class I and class II restriction was observed [18]. Autologous DCs that were generated from MM patients have been shown to efficiently endocytose different classes of Id protein, and autologous Id-specific CTLs lines containing both $\mathrm{CD} 4^{+}$and $\mathrm{CD}^{+} \mathrm{T}$ cells that were generated by Id-pulsed DCs significantly recognized and killed the autologous primary myeloma cells in vitro $[18,19]$. Until now, the various studies of DC-based Id vaccination in MM have been reported [2027]. Although Id-specific CTLs and immune response could be induced in some patients, clinical responses have been observed rarely in few patients after vaccination [22]. To improve the effectiveness of DC vaccination, the Id-pulsed DCs were vaccinated in combination with KLH or cytokine IL-2 in MM patients [21, 23, 26]. However, even both cellular and antibody responses have been observed, the clinical response also was not improvement following vaccinations. The reasons for these results may be attributed mainly to the Id protein as a weak antigen, and the use of immature DCs in some studies [20, 28, 29].
2.2. Myeloma-Associated Antigens-Loaded DC. Tumor-associated antigens (TAAs) have been identified in many tumor types including solid tumors and hematological malignancies. The highly specific TAAs overexpress in increasing amounts in malignant cells were the greatest potential for clinically useful assays. A variety of myeloma-associated antigens have been identified in MM patients, which possibility provides an immune response by DC-based vaccine. T cells from myeloma patients can recognize a variety of TAAs, which suggesting that the $\mathrm{T}$ cell has the capacity to kill myeloma cells selectively if these clonal populations can be activated and expanded effectively by a potent TAA. Many potential TAAs in MM have been investigated including polymorphic epithelial mucin (MUC1), human telomerase reverse transcriptase (hTERT), PRAME, HM1.24, SP17, Wilms' tumor I (WTI), Dickkopf-1 (DKK1), or member of cancer germ-like family (MAGE, GAGE, BAGE, LAGE, NYESO-1) [30-35]. Among the various TAAs, some have been tested as peptide vaccines and only a few of them has been tested in vitro to induce TAA-specific CTLs response via loading the potent TAA to DCs in MM. The first TAAs pulsed with DCs in MM was MUC1, which was expressed on all of MM cell lines and primary myeloma cells and in sera of MM patients. Vaccination with MUC1 antigen has not been studied in MM patients, but MUC1-specific CTLs that were induced in vitro using peptide-pulsed DCs or plasma cell RNA-loaded DCs efficiently killed not only target cells pulsed with the antigenic peptide but also MM cells $[31,36]$. NY-ESO-1 is the most immunogenic of the cancer testis antigens, which are expressed in a variety of tumors, while their presence in normal tissue is limited to the testis and placenta [35]. In MM, expression of NY-ESO-1 has been correlated with more advanced disease [37]. Spontaneous humoral and $\mathrm{CD}^{+} \mathrm{T}$ cell-mediated responses to NY-ESO1 have been identified in patients with advanced disease $[35,37]$. The in vitro monocyte-derived DCs transduced with the PTD-NY-ESO-1 protein can induce $\mathrm{CD}^{+}$cellular antitumor immunity superior to that achieved with NY-ESO-1 protein alone [30]. Sperm protein 17 (Sp17), the other immunogenic TAA, has been used as a tumor antigen to load into DCs. Sp17-specific HLA class I restricted CTLs were successfully generated by DCs that have been loaded with a recombinant Sp17 protein and the CTLs were able to kill autologous tumor cells that expressed Sp17 $[38,39]$. The over-expression of hTERT on MM compared to normal cells indicated that this telomerase could be used as tumor antigen to induce antitumor immune responses. hTERT was capable of triggering antitumor CTL responses and kill hTERT ${ }^{+}$ tumor cells [40]. Recently, the CTLs that were stimulated by hTERT- and MUC1-derived nonapeptides loaded DCs were successfully able to kill myeloma cell line [41]. DKK1, a novel protein that is not expressed in most normal tissues but is expressed in almost myeloma cells, could be a potentially important antigenic target for antimyeloma immunotherapy. DKK1-specific CTLs that were generated by DCs pulsed with DKK1 peptides were specifically lysed autologous primary myeloma cells and DKK1-positive cell line [34]. In general, TAAs could be a major interest in immunotherapy in MM. Taken together, the data support DC immunotherapy with 
TAAs as being a promising immunotherapy to support to clinical trials in MM.

\section{Whole Tumor Antigen-Loaded DC}

An alternative to Id protein- or TAA-based immunotherapy in $\mathrm{MM}$ is to use other tumor antigens that derived from whole tumor preparation to improve the efficacy of the DC vaccination in patients with MM. DCs loaded with antigens derived from whole tumor cells can improve the antitumor response and that limits the risk for immunological escape. There have been increasing reports of these alternative approaches, such as DCs pulsed with myeloma lysates [42-44], DCs pulsed with myeloma apoptotic bodies [ $43,45,46]$, DCs transfected with myeloma-derived RNA [36], DCs pulsed with myeloma-derived heat shock protein (HSP) gp96 $[47,48]$, or DC-myeloma cell hybrids [49-51]. These techniques have the advantage of allowing the presentation of multiple epitopes to MHC on DCs, therefore can induce polyclonal T-cell response from many potentially unknown TAAs and reduce the probability of immune escape by single TAA. DCs loaded with myeloma cell lysates demonstrated much stronger cytotoxicity against autologous plasma cells than did those by Id protein-pulsed DCs, which suggested the superiority of the myeloma cell itself as a source of a tumor antigen compared with the Id protein [44]. In other myeloma model, DCs pulsed with purified and optimized myeloma cell lysate were shown to generate CTLs that killed autologous tumor cells but not against mismatch HLA cell lines or K562 cell lines in vitro [43]. The apoptotic bodies derived from either myeloma cell lines or patient's myeloma cells also have been used as tumor antigen to loading with DCs. Interestingly, apoptotic bodies were shown to be more effective than cell lysate at inducing CTLs against autologous myeloma cells [42]. Heat shock proteins (HSPs) are a class of functionally related proteins whose expression is increased when cells are exposed to elevated temperatures or other stress. Tumor-derived HSPs, such as HSP70 and gp96, are immunogenic and potent in stimulating the generation of tumor-specific CTLs. The myeloma-derived gp96 loaded DCs were used to generate tumor-specific CTLs that were able to lyse myeloma tumor cells but not normal blood cells in a MHC class I restricted manner [47, 48]. In other way, the fusions of autologous DCs with patient-derived tumor cells have been developed. Fusion cells can stimulate both helper and cytotoxic T-cell responses through the presentation of internalized and newly synthesized antigens [51]. In mouse MM models, vaccination with DCs fused with either plasmacytoma cells or tumor cells that were genetically modified to express CD40L resulted in eradication of disease in tumorbearing animal and protective against subsequent tumor challenge in animals $[49,50]$. In general, the production of DC vaccine by using whole tumor antigens has become promising in order to induce immunotherapy against MM.

\section{DC-Based Vaccine Clinical Trials}

Clinical trials of DC-based vaccine for MM have been restricted until now. The trial protocol and responses are summarized in Table 1. ALmost of the clinical trials were related with using Id-pulsed DC alone or in combination with adjuvant such as cytokines or KLH. In the decade after the first DC-based Id vaccination was started at Stanford University, the results of clinical trials were limited. In general, the majority of clinical trials conducted using Idpulsed DCs showed immune responses. However, the clinical responses were unsatisfactory, mainly due to the poor immunogenicity of the Id protein. More recent results demonstrated improved clinical response by DC-based Id vaccination [26, 27]. Therefore, DC-based Id vaccination is going to a possible way to induce the specific $\mathrm{T}$ cell responses in myeloma patients. Further trials with increasing numbers of patients are needed to increase the rate of responses.

Most recently, phase I study was undertaken, in which patients with MM were vaccinated with an autologous DC/ tumor cell fusion in combination with GM-CSF administration on the day of DC vaccination [52]. Vaccine generation was successful in 17 of the 18 patients. The expansion of circulating $\mathrm{CD}^{+}$and $\mathrm{CD} 8^{+} \mathrm{T}$ cells reactive with autologous myeloma cells in 11 of 15 evaluable patients were detected. A majority of patients ( 11 of 16) with advanced disease demonstrated disease stabilization, with three patients showing ongoing stable disease at 12, 25, and 41 months. Interestingly, antibody response against some TAAs, such as regulators of G-protein signaling 19 (RGS19), HSP90, BRCA1-associated protein (BRAP), was also detected. So, vaccination with DC/MM fusions was feasible and may provide a new source of DC-based vaccines for the development of immunotherapy against $\mathrm{MM}$.

A commercial product is currently being tested in phase III trial (Mylovenge, Dendreon Corp, Seattle, WA, USA). Mylovenge (APC8020) is conducted by pulsing autologous DCs with the patient's Id. A recent report of this commercial product showed that the long-term survival of those receiving the vaccine compared to all other patients with $\mathrm{MM}$ who underwent autologous HSCT [53]. This approach needs further testing in phase III trial to confirm the clinical response and define the role of this DC vaccine in MM. We are also conducting phase I/II clinical trial using type-1-polarized DCs loading with tumor antigens derived either from allogeneic myeloma cell line or patient's autologous-/allogeneic-myeloma cells in combination with chemotherapy in patients with MM after autologous HSCT.

\section{How to Improve DC Vaccination in MM?}

During recent decades, cancer immunotherapy using DCbased vaccines has been used as therapeutic in patients with cancer including MM patients, however, while a few number of patients can really induce tumor regressions, one of the most common responses of the current DC vaccination is only a demonstration of antigen-specific immune responses, but no evidence of tumor regression. This unexpectation provides the new strategy for the treatment of cancer in which the intrinsic abilities of the immune system response to the DC vaccine has been modified to enhance the efficacy of vaccination. Several studies indicate that the immune 
TABLE 1: Summary of clinical trials of DC-based vaccine for MM.

\begin{tabular}{|c|c|c|c|c|c|}
\hline Author & DC type & TA & Adjuvant & Immune responses & Clinical responses \\
\hline Liso et al. & $\mathrm{imDC}$ & Id & $\pm \mathrm{KLH}$ & 4/24 Id-specific & $17 / 26 \mathrm{SD}$ \\
\hline Lim et al. & imMo-DC & Id & $\mathrm{KLH}$ & $\begin{array}{l}\text { 5/6 Id-specific; } 2 / 6 \text { Id-specific } \\
\text { IFN- } \gamma ; 3 / 6 \text { increase in } \\
\text { Id-specific CTL frequency }\end{array}$ & 6/6 PD \\
\hline $\begin{array}{l}\text { Reichardt } \\
\text { et al. }\end{array}$ & $\operatorname{imDC}$ & Id & none & $\begin{array}{l}\text { 2/12 Id-specific proliferation; } \\
\text { 1/3 Id-specific CTL }\end{array}$ & $\begin{array}{c}2 \text { relapse; } 8 / 10 \mathrm{PD} ; 2 / 10 \\
\mathrm{SD}\end{array}$ \\
\hline Titzer et al. & CD34-DC & Id & none & $\begin{array}{l}\text { 4/10 Id-specific } \mathrm{T} \text { cell } \\
\text { proliferation; } 1 / 10 \text { decreased } \\
\text { BM plasmacytosis }\end{array}$ & 1/10 SD; 9/10 PD \\
\hline Cull et al. & imMo-DC & Id & none & $\begin{array}{l}2 / 2 \text { Id-specific T cell } \\
\text { proliferation; no Id-specific } \\
\text { CTL response }\end{array}$ & 2/2 PD \\
\hline Yi et al. & $\mathrm{mMo}-\mathrm{DC}$ & Id & Il-2 & $\begin{array}{l}2 / 5 \text { Id-specific } \mathrm{T} \text { cell } \\
\text { proliferation; } 5 / 5 \text { Id-specific B } \\
\text { cell proliferation; } 4 / 5 \\
\text { Id-specific IFN- } \gamma\end{array}$ & 1/3 PR; $3 / 5 \mathrm{SD} ; 1 / 5 \mathrm{PD}$ \\
\hline $\begin{array}{l}\text { Bendandi } \\
\text { et al. }\end{array}$ & mMo-DC & Id & none & $\begin{array}{l}\text { 4/4 anti-KLH response; } 2 / 4 \\
\text { Th1 cytokines response }\end{array}$ & $1 / 4 \mathrm{SD} ; 3 / 4 \mathrm{PD}$ \\
\hline Lacy et al. & $\begin{array}{c}\text { APC8020 } \\
\text { (Mylovenge) }\end{array}$ & Id & none & None reported & $\begin{array}{c}\text { 6/26 CR; } 2 / 26 \text { PR; } 19 / 27 \\
\text { SD overall survival: } 5.3 \\
\text { years of followup for } \\
\text { alive patients }\end{array}$ \\
\hline Lacy et al. & CD40 L-DCs & Id & KLH & $\begin{array}{l}\text { 9/9 Id-specific IFN- } \gamma ; 5 / 9 \\
\text { Id-specific CTL response; 8/9 } \\
\text { anti-KLH response }\end{array}$ & $\begin{array}{c}\text { 6/9 SD; } 3 / 9 \text { slowly PD } \\
\text { 4/6 continue SD after } 5 \\
\text { years }\end{array}$ \\
\hline $\begin{array}{l}\text { Rosenblatt } \\
\text { et al. }\end{array}$ & $\begin{array}{l}\text { DC/tumor } \\
\text { fusion }\end{array}$ & & GM-CSF & $\begin{array}{l}11 / 15 \text { CD } 4 \text { and CD8 response } \\
\text { with autologous myeloma } \\
\text { cells; } 5 / 5 \text { tested anti-MUC1 } \\
\text { response }\end{array}$ & $\begin{array}{c}11 / 16 \text { SD }(3 / 11>1 \text { years } \\
\text { SD; } 8 / 112.5-5 \text { months } \\
\text { SD })\end{array}$ \\
\hline Rollig et al. & mMo-DC & Id & KLH & $\begin{array}{l}\text { 5/9 Id-specific T cell } \\
\text { proliferation; } 8 / 9 \text { Id-specific } \\
\text { cytokines response }\end{array}$ & $\begin{array}{l}\text { 3/9 M protein decrease; } \\
\text { 5/9 M protein stable }\end{array}$ \\
\hline
\end{tabular}

DC: dendritic cell; TA: tumor antigen; imDC: immature DC; Mo-DC: monocyte-derived DC; Id: idiotype; mMo-DC: mature Mo-DC; KLH: keyhole limpet hemocyanin; CTL: cytotoxic T lymphocyte; PD: progressive disease; PR: partial response; SD: stable disease; CR: complete response.

system of cancer patients can recognize and kill tumors; however, some cancer patient cannot induce the immune response against tumor. In particularly, ex vivo DCs are usually generated from cancer patients, however, patients with cancer including MM have basically dysfunctional DCs [54-57]. DC function is mainly affected by the microenvironment in which they can stimulate immune response [58]. The present of several immunosuppressive factors in tumor microenvironment including the high production of inhibitory cytokines (interleukin-(IL-) 10, transforming growth factor beta (TGF- $\beta$ ), vascular endothelial growth factor (VEGF), and IL-6), the activation of STAT3, the expansion of Treg cells, and the significant suppressive effect of MDSC has been investigated [55-57, 59-64]. Therefore, the recent new idea now is how to improve the efficacy of DC vaccine to increase the effectiveness of vaccination against tumors.

For improving clinical outcomes using DC-based immunotherapy, there have been increasing reports of alternative approaches, such as better cytokine combinations to enhance
DC function, effective tumor antigens to induce specific CTLs, or modifying signal transcriptions to overcome defective DC function. Our experience in the DC research field has revealed several key points to improve DC vaccination in cancer patients including MM (Figure 1).

5.1. Enhancing the Maturation and Activation of DCs by Th1 Polarizing Cytokines. For effective induction of tumorspecific immune responses in the field of DC vaccination, the DCs should have potency to stimulate T cells, to produce high levels of Th1-polarized cytokines (IL-12p70), to trigger Th1 polarizing capacity, and to migrate through lymphatic vessels to interact with $T$ cells. The initial success of the therapeutic vaccines involving immature or partiallymature "first-generation" DCs has been reported [65]. However, such DCs express suboptimal levels of costimulatory molecules, and constitute a weaker immunogen than the subsequently implemented mature DCs, constituting the "second generation" of clinically applied DCs (sDCs). sDC vaccines induced by the IL- $1 \beta /$ TNF- $\alpha /$ IL-6/prostaglandin 


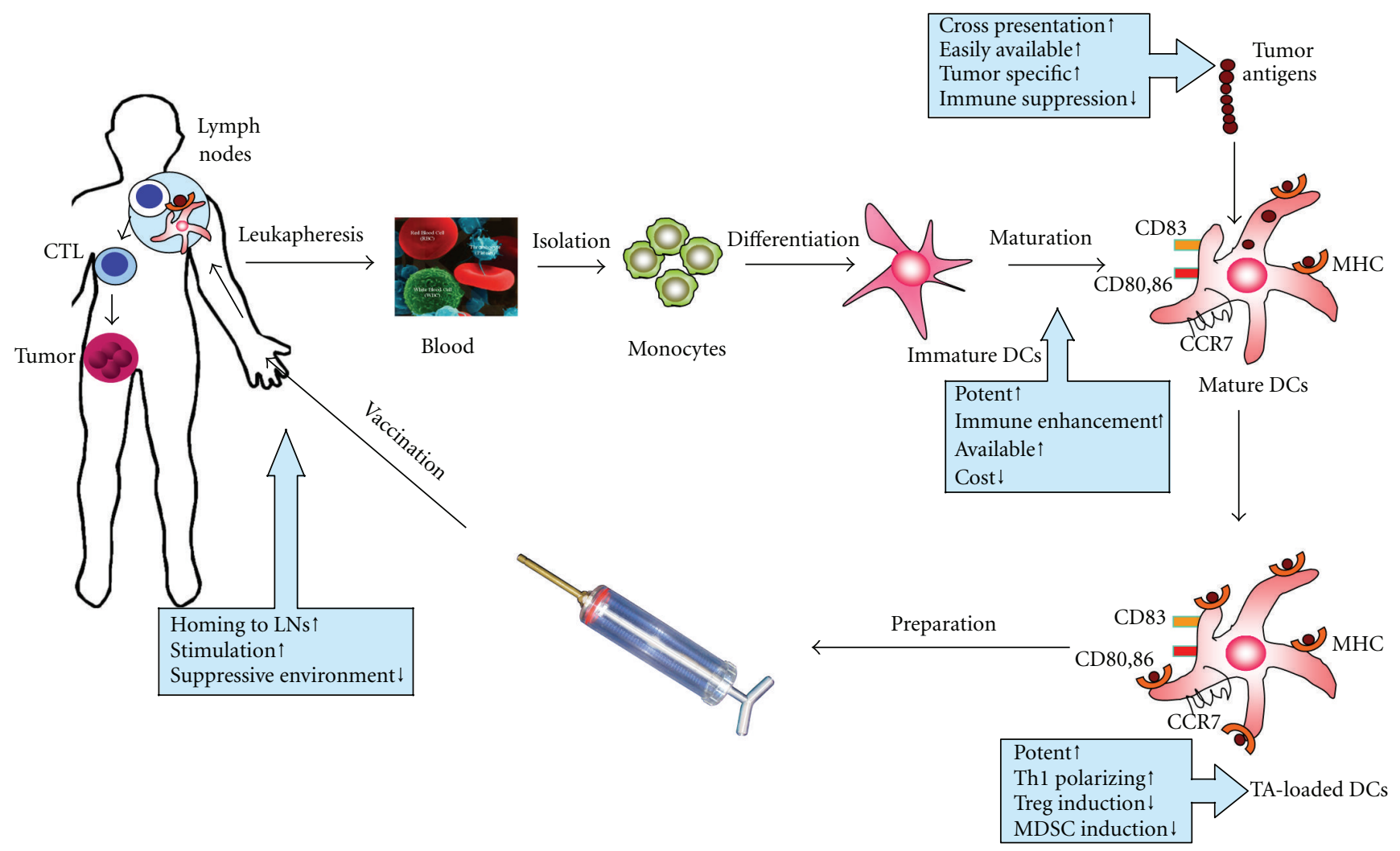

FIGURE 1: Key points to improve DC vaccination in cancer patients. CTL: cytotoxic T lymphocyte; DCs: dendritic cells; TA: tumor antigen; LNs: lymph nodes; Treg: regulatory T cell; MDSC: myeloid-derived suppressor cell.

$\mathrm{E}_{2}\left(\mathrm{PGE}_{2}\right)$ cytokine cocktail have been developed [66]. Such DCs are fully mature DCs with high expression of costimulatory molecules, high expression of CCR7, and high migratory responsiveness to $\mathrm{LN}$-associated chemokines; they have been widely tested in clinical trials. However, to date, the sDC vaccines have limitations that include the mediation of Th2 polarization, promotion of DC secretion of the immunosuppressive cytokine IL-10, inability to induce effectively the Th1-type response (because $\mathrm{PGE}_{2}$ abolishes the secretion of IL-12p70), and high activity of such DCs in activating Treg cells $[67-70]$.

Several investigators, including our group, have tried to develop the potent DCs for inducing effective tumor-specific immune responses. In an attempt to increase DC potency using cytokine combinations, $\alpha$-type-1-polarized DCs ( $\alpha \mathrm{DC} 1 \mathrm{~s})$ that are induced to mature using the $\alpha \mathrm{DC} 1$-inducing cytokine cocktail IL- $1 \beta$, TNF- $\alpha$, IFN- $\alpha$, IFN- $\gamma$, and polyinosinic: polycytidylic acid [poly(I:C)] has been developed to generate strong functional CTLs in several diseases, on average 20-fold higher compared to sDCs $[71,72]$. Recently, we successfully generated $\alpha \mathrm{DC} 1$ s from a patient with MM with high expression of costimulatory molecules, significant production of IL-12p70, and potent generation of myelomaspecific CTLs $[43,46]$. Such a novel appropriate strategy provides a way to improve the potency of ex vivo generated DCs for cancer therapy.
5.2. Enhance the Maturation and Activation of DCs by Natural Product as TLR Signaling. Ursolic acid (URC) is isolated from Uncaria rhynchophylla and phytochemically classified as triterpene. Triterpene compounds have been identified as a unique class of natural products possessing diverse biological activities. Recently, we have reported that URC activates human DCs in a fashion that favors Th1 polarization via the activation of IL-12p70 dependent on TLR2 and/or TLR4 and induces the production of IFN- $\gamma$ by $\mathrm{CD}^{+}$naïve T cells [73]. In addition, the combination of URC and IFN- $\gamma$ enhance the activation of DCs, namely, the enhancement of Th1 cells polarization that induced by IFN- $\gamma$ depends on the activation of IL-12p70 and independent on TLR4 [74]. The potential of natural product to enhance DC maturation and activation has important implications for the use of DCs as cancer vaccines.

\subsection{Enhance the Cross-Presentation of DCs by Tumor Associat-} ed Antigens. As described above, the results of immunotherapy with Id-pulsed DCs have been unsatisfying. The use of TAA can induce the higher immune response compared to Id. Although a single TAA has the possibility to induce the antitumor immune responses against MM, tumors may escape immune recognition by downregulating expression of a particular antigen. However, TAA can induce autoimmunity. Several TAAs have been detected in normal tissues. In 
addition, only a small number of tumor samples from MM patients showed a similar level of TAA expressing, limiting its usefulness for using TAA in MM. Therefore, to overcome the effect of TAAs-based immunotherapy, our group tries to use other tumor antigens that improve the cross-presentation of the DC vaccination in patients with MM.

The selected antigen should possess the best characteristics to induce high cross-presentation, be tumor specific, be easily available, and be unable to induce immune suppression. Whole tumor antigens is the best tumor antigen, which has been selected by many investigator including myeloma cell lysates [42-44], apoptotic bodies from myeloma cell line $[43,45,46]$. In practical terms, there are a number of patients with $\mathrm{MM}$, who have less than $50 \%$ of myeloma cells in the bone marrow at the time of diagnosis or during progression of the disease. When mononuclear cells from the bone marrow are used as a source of tumor antigens, there is the potential of contamination with normal cells, especially lymphocytes. Thus, it is necessary to use purified and optimized myeloma cells, if possible, as a source of tumor antigen for the generation of myeloma-specific CTLs stimulated by DCs [43]. We have shown that the function of the DCs was affected by the concentration of myeloma cell lysates (i.e., higher concentrations of lysates suppress $\mathrm{T}$ cell stimulatory capacities more than lower concentration of lysates). Also, the optimization of the lysate concentration did not demonstrate any inferiority in functions, such as $\mathrm{T}$ cell stimulatory capacities and cytotoxicities, of the DCs compared with other antigens, such as apoptotic bodies of myeloma cells or formalin-fixed myeloma cells. CTLs that were generated by purified and optimized myeloma cell lysates pulsed with DCs demonstrated much stronger cytotoxicity against autologous plasma cells. These findings indicate that it is important to optimize the concentration of myeloma cell lysates that were loaded onto DCs to potentiate their function.

The use of whole tumor cells, instead of single antigens, may help to enhance antitumor effects but target multiple tumor variants and counteract tumor immune evasion. However, it is impractical to obtain sufficient amounts of purified autologous myeloma cells for tumor antigens in the clinical setting of patients with MM. As an alternative source of tumor-relevant antigens, allogeneic tumor cells or established cancer cell lines have been used to overcome this limitation in various tumors $[43,46,75,76]$. Allogeneic myeloma cell lines used as universal tumor antigens could substitute for an original tumor cell collection and make the culture of tumor cells easier. In clinical practice, allogeneic myeloma cell lines might be an effective source of universal tumor antigen that could be used to load DCs for the generation of myeloma-specific CTLs in MM patients. Tumor antigens that derived from irradiated allogeneic myeloma cell line when loaded with DCs could generate myeloma-specific CTLs against autologous myeloma cells in patients with MM $[45,46]$. The success of using an allogeneic myeloma cell line as tumor antigen led to the possibility that allogeneic myeloma cells could be also used as a viable source of tumor antigen in the context of appropriate major MHC alleles to autologous CTLs. We investigated the possibility of DC therapy using autologous DC loaded with apoptotic allogeneic myeloma cells from the matched monoclonal subtype of myeloma patients and showed that the CTL generated by these tumor antigens loaded DCs could generate myelomaspecific CTLs against autologous myeloma cells in patients with MM [77]. These findings suggested that allogeneic myeloma cell lines and the allogeneic matching monoclonal immunoglobulin subtype of myeloma is the effective tumor antigen capable of inducing functional CTLs against patients' own tumor cells.

5.4. Blocking the Immunosuppressive Activity. The suppressive effects of tumor cells during DC generation have been explained previously by the ability of the tumor microenvironment to suppress DC differentiation $[60,78]$. In addition, patients with MM have DCs that are functionally defective, evidenced by the decreased number of circulating precursors of DCs as well as impaired T-cell stimulatory capacity [5557]. DCs in MM patients are a target of tumor-associated suppressive factors, such as IL-10, TGF- $\beta$, VEGF, and IL6 , resulting in their aberrant functions and impaired development of effector functions in tumor-specific lymphocytes $[55,56]$. These factors can influence the activation of STAT3 and extracellular signal-regulated kinase (ERK) phosphorylation, resulting in hyperactivation of STAT3 and ERK, which may be responsible for defective DC differentiation [60, 79]. In addition to generation of potent and specific tumor antigen-loaded DCs for vaccination, alternative methods have attempted to restore defective DC function and to enhance DC function in MM. Enhanced immune-mediated antitumor effects of DCs have been reported following the inhibition of the janus-activated kinase 2 (JAK2)/STAT3 pathway [80-82], inhibition of p38 or activation of the MEK/ERK or mitogen-activated protein kinase (MAPK) pathways, and neutralization of IL-6 [83]. Recently, we reported that the inhibitory factors and abnormal signaling pathways of DCs during maturation with tumor antigen might be responsible for the defective activity of DCs in MM and suggested that the way to overcome these abnormalities is by neutralizing the signaling that would lead to a suppressed immune response [84]. More recently, we are developing of the strategies that recovering dysfunction of DCs caused from loading tumor antigen through the treatment of a combination of the selective JAK/STAT3 signaling pathway inhibitor (JSI-124) and the proteasome inhibitor (Bortezomib) onto myeloma cells (unpublished data). We reported that pretreatment of myeloma cells with combination of JSI-124 and bortezomib can recover DC dysfunction from loading the dying myeloma cells through the upregulation of Hsp90 and the downregulation of STAT3 phosphorylation and inhibitory cytokines production, and these DCs can generate to potent myeloma-specific CTLs.

\subsection{Natural Killer (NK) Cells and Helper Functions during Induction of Type 1 Immunity by DCs. The other strategy to induce potent DCs from patients with MM was the use of a "helper" cell to promote type 1 polarization of DCs. NK cells are rapidly homing to the sites of infection and con- trol the immune response in viral infections. Indeed, it has}


been demonstrated that NK cells play a major immunoregulatory role in the development of a protective T-cellmediated immunity against intracellular pathogens and cancer [85-87]. Such "helper" activity of NK cells is at least partially mediated by the functional modulation of DCs, the phenomenon depending on the production of IFN- $\gamma$ and TNF- $\alpha$ by activated NK cells [85-87], and associated with enhanced cross-presentation of tumor antigens and the induction of Th1 and CTL responses $[45,88,89]$. Recent data from our and other groups demonstrate that such NK-DC interaction promotes the subsequent induction of tumor-specific responses of $\mathrm{CD}^{+}$and $\mathrm{CD} 8^{+} \mathrm{T}$ cells, allowing NK cells to act as "helper" cells in the development of the type 1 DCs in responses against cancer $[45,88,89]$. Resting NK cells that are activated in the presence of TLR agonist, IL-2, and IFN- $\alpha$ can induce DCs from patients with MM maturation and enhance IL-12p70 production in vitro. These potent DCs can be developed to generate strong functional CTLs against myeloma cells compared to sDCs [45].

5.6. Treg Cells and MDSC Regulation. Therapeutic DC vaccines against cancer not only need to be highly effective in inducing the expansion of tumor-specific $\mathrm{T}$ cells, but they also need to avoid interaction and induction of Tregs. However, MM induces immune paresis [54]. Tumors are able to escape immune surveillance by down-regulation of immune responses as well as through the production of immunosuppressive cytokines by the tumor cells or by activation of suppressor cells such as regulatory $\mathrm{T}$ cells (Treg) and myeloid-derived suppressor cells (MDSCs) [90]. Dysregulation of natural $\mathrm{CD} 4^{+} \mathrm{CD} 25^{+} \mathrm{T}$ regulatory (Treg) in MM has been reported [91]. Tregs are a group of immunosuppressive $\mathrm{T}$ cells that have been implicated in the suppression of tumor immunity [92]. A higher number of Tregs were reported in myeloma capable of suppressive activity at $\mathrm{T}$-cell stimulation [61]. Recently, the discovery of MDSCs revealed these cells as potent suppressors of tumor immunity and, therefore, a significant impediment to cancer immunotherapy [63]. MDSCs can suppress the activation of T cells, B cells, NK cells and NKT cells. In contrast, MDSCs can enhance the induction of Tregs [64]. Recently, a human study reported that the proportion of $\mathrm{CD}^{+} \mathrm{FoxP}^{+}$Treg cells and $\mathrm{CD}^{+} 4^{+} \mathrm{HLA}-$ $\mathrm{DR}^{- \text {low }}$ MDSC was increased in patients with $\mathrm{MM}$ at diagnosis was described [62]. These cells were functionally intact as they were able to inhibit proliferation of both CD4 and CD8 T cells illustrating that this cell fraction is also distorted in patients with MM [62].

The type-1-polarized DCs were demonstrated to suppress the secretion of CCL22 (Treg and Th2 type attracting chemokines), enhance the secretion of CCL5 and CXCL10 (Th1 and effector T-cell-attracting chemokines), and suppress the induction of Tregs compared to sDCs or $\mathrm{PGE}_{2}-$ matured DCs [93]. In addition, to enhance the antitumor effectiveness of DC-based vaccines in preclinical in vivo mouse models, we have developed several models of combination therapy of DCs with an immunomodulatory drugs, such as cyclophosphamide or lenalidomide. Cyclophosphamide is frequently used to enhance or augment the antitumor effects in cancer immunotherapy [94]. The possible effect of cyclophosphamide to enhance the antitumor efficacy of DC vaccine may be due to the increasing proportion of IFN- $\gamma$ secreting lymphocytes in combination with the suppressing proportion of $\mathrm{CD}^{+} \mathrm{CD}^{+} 5^{+} \mathrm{FoxP}^{+}$Treg cells in tumor-bearing mice [95]. The result of a clinical trial using allogeneic DC vaccine combined with low-dose cyclophosphamide has revealed that the combination therapy could induce stronger antitumor response compared with DC vaccine alone [96]. Recently, we developed a combination therapy in mouse cancer model which showed that a single administration of low-dose cyclophosphamide before the first DC vaccination augmented the antitumor effects of DC vaccine to eradicate tumor completely and consequently prolonged the survival of vaccinated mice [89]. Lenalidomide is a potent anti-myeloma drug which the activity are related with immunomodulatory properties. Lenalidomide inhibits Treg expansion and FoxP3 expression on cancer patients [54]. Our results show that the reduction of suppressor cells including Treg and MDSC in spleens of lenalidomide vaccinated mice in MM model (unpublished data). Therefore, the combination of DCs with chemotherapy, especially immunomodulatory drugs, could regulate and inhibit the expansion of immunosuppressor cells and significantly improve the antitumor effects.

5.7. Regulation the Migratory Pattern of DCs. DCs generated in vitro for vaccination protocols that can target a local lymph node are highly sought, but difficult to achieve in practice. Type-1-polarized DCs, with higher levels of IL-12p70 and potent CTL generation targeting, are, however, limited by their migratory capacity to primary lymph organs due to the relatively lower expression of CCR7 compared to sDCs. We recently reported on the nature of the enhancement of the migratory phenotype of DCs. The first important mediator in the mobilization of DCs to lymph nodes is CCR7. However, upregulation of CCR7 alone by DCs is insufficient to drive DC migration toward CCL19 and CCL21. Upregulation of $\mathrm{CD} 38$ and downregulation of $\mathrm{CD} 74$ regulate DC migration in vitro and in vivo $[97,98]$. By regulating CD38, CD74, and CCR7 expression on DCs, types I and II IFNs have synergistic effects in the presence of TLR agonists on the regulation of DC migration and may provide a novel approach to improving vaccination efficacy [99].

\section{Can Cellular Immunotherapeutic Methods Improve MM?}

In terms of treatment strategies in MM, the widespread use of the novel therapies, such as thalidomide, bortezomib and lenalidomide, has now significantly improved the prognosis, and outcome for patients [100]. The use of these novel therapies in the primary setting together with conventional chemotherapeutics into early treatment has driven most of the benefit. However, relapsed and refractory disease remains an area of challenge, where once prior therapy with immunomodulatory agents and proteasome inhibition has failed, the prognosis remains very poor. An important challenge that therefore emerges is a risk-adapted approach to MM therapy [101]. The application of some novel antitumor 


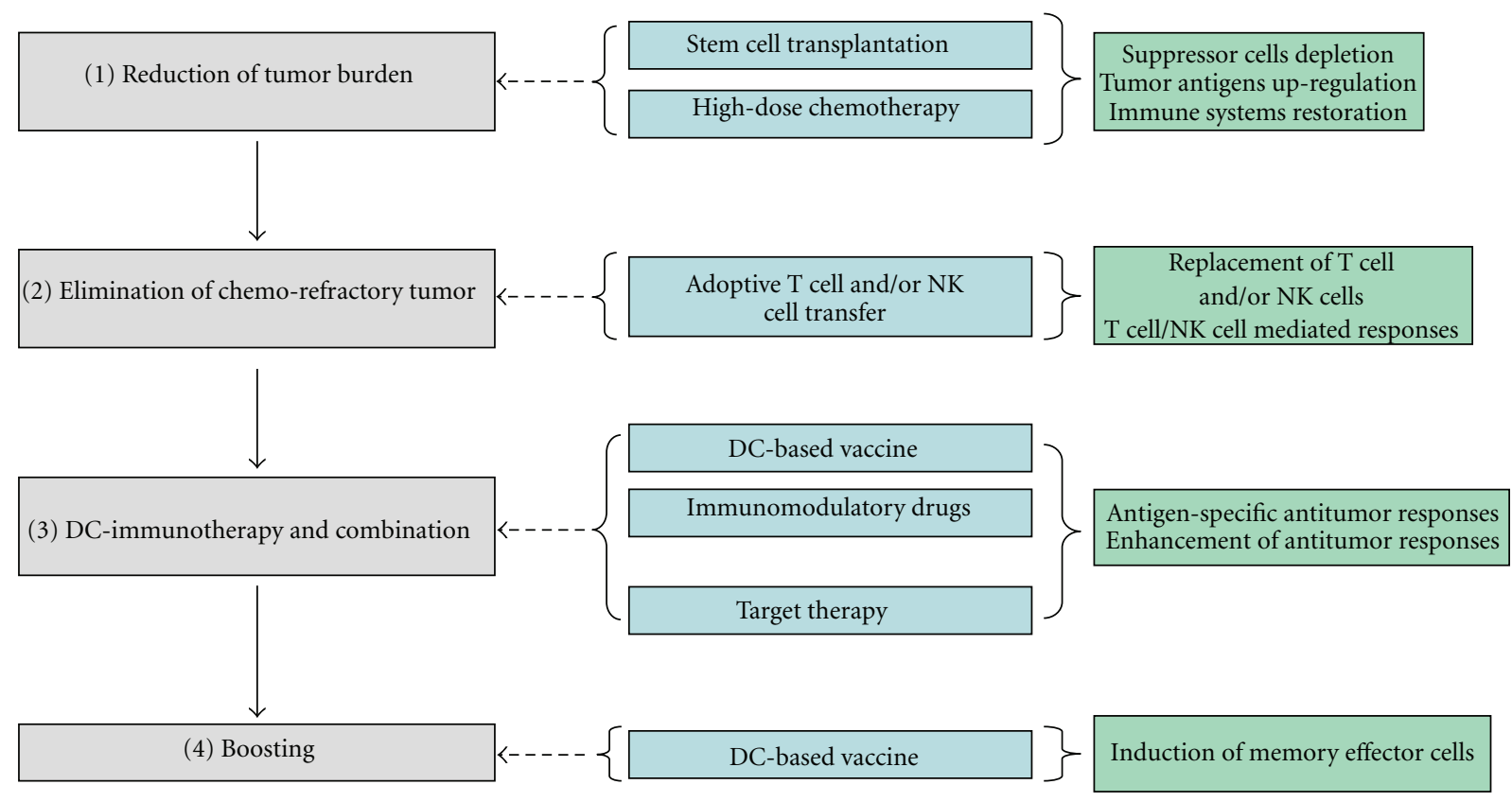

FIGURE 2: Current suggestion of DC-based vaccines for patients with MM. (1) Vaccination requires the restoration immune system and the tumor burden is low; (2) new T-cell repertoire induction and elimination of relapse/refractory disease; (3) DC vaccination in alone or combination; (4) boosting the antitumor immune responses.

agents reveals the new option for high-risk MM. Autologous and allogeneic stem cell transplantation also still remains the important therapeutic modality for these patients.

Several studies investigated the point to an inherent immune system dysregulation that cause the complication of immunotherapeutic strategies for MM. The dysregulation in immune cells, the overproduction of immunosuppressive cytokines, and the proliferation of regulatory $\mathrm{T}$ cells and MDSCs have been associated with many defects in the host immune system of patients with MM, particularly in the advanced MM patients [54]. Adoptive transfer of T cells and NK cells may represent a new immunotherapy for multiple myeloma. One strategy to improve responses to vaccination involves combining active vaccination with adoptive $\mathrm{T}$ cell transfer [102]. Adoptive transfer of activated NK cells in conjunction with IL-2 to myeloma-bearing mice resulted in prolonged survival compared with treatment with either IL2 or activated NK cells alone and the antimyeloma effect was more potent with a higher dose of NK cells [103].

For the DC-based vaccine, several clinical trials applied to the seeing of MM patients after ASCT and these approaches may reasonable to increase therapeutic effect of DC-based vaccine in term of minimal residual disease [20, 22-24, 28]. Furthermore, recent study has shown that the immune competence of MM patients can be restored following high dose chemotherapy and ASCT by a combination of vaccination and adoptive T-cell therapy [102]. Practically, patients with refractory and relapsed MM may be not good candidates to apply the DC-based vaccine, but combination approach using DC-based vaccine to reduce tumor cells and immune modulation agents, such as lenalidomide and low-dose cyclophosphamide, to overcome tumor microenvironment will be helpful to improve the disease status. The time point of DC-immunotherapy application was described in Figure 2.

\section{Conclusion}

Despite their relative limitations, the data from recent clinical studies have suggested that DC-based vaccine may be a potential therapy in inducing the rate of tumor responses and prolonging the survival of patients with MM. In an attempt to increase DC-based potency and improve immune responses following vaccination, further investigations of additional tools to identify the alternative tumor antigens uniquely or specifically expressed on myeloma cells are needed, to recover or restore the dysfunction of DCs in MM patients, to induce $\mathrm{T}$ cells with the desirable effector functions rather than regulatory functions, to migrate into lymph nodes to stimulate $\mathrm{T}$ cells, and to clarify the ability of tumor-specific CTLs to recognize and kill tumor cells. In our expectation, type-1-polarized DCs can be developed to generate strong functional CTLs. The allogeneic myeloma cell lines or allogeneic myeloma cells might be an effective source of universal tumor antigen that could be used to load to the DC1s for the successful generation of myelomaspecific CTLs. Eventually, the combination therapy, in which a DC vaccine is combined with either alternative therapy including chemotherapy, radiation therapy, molecular target therapy or other immunotherapy (adoptive therapy, NK cells 


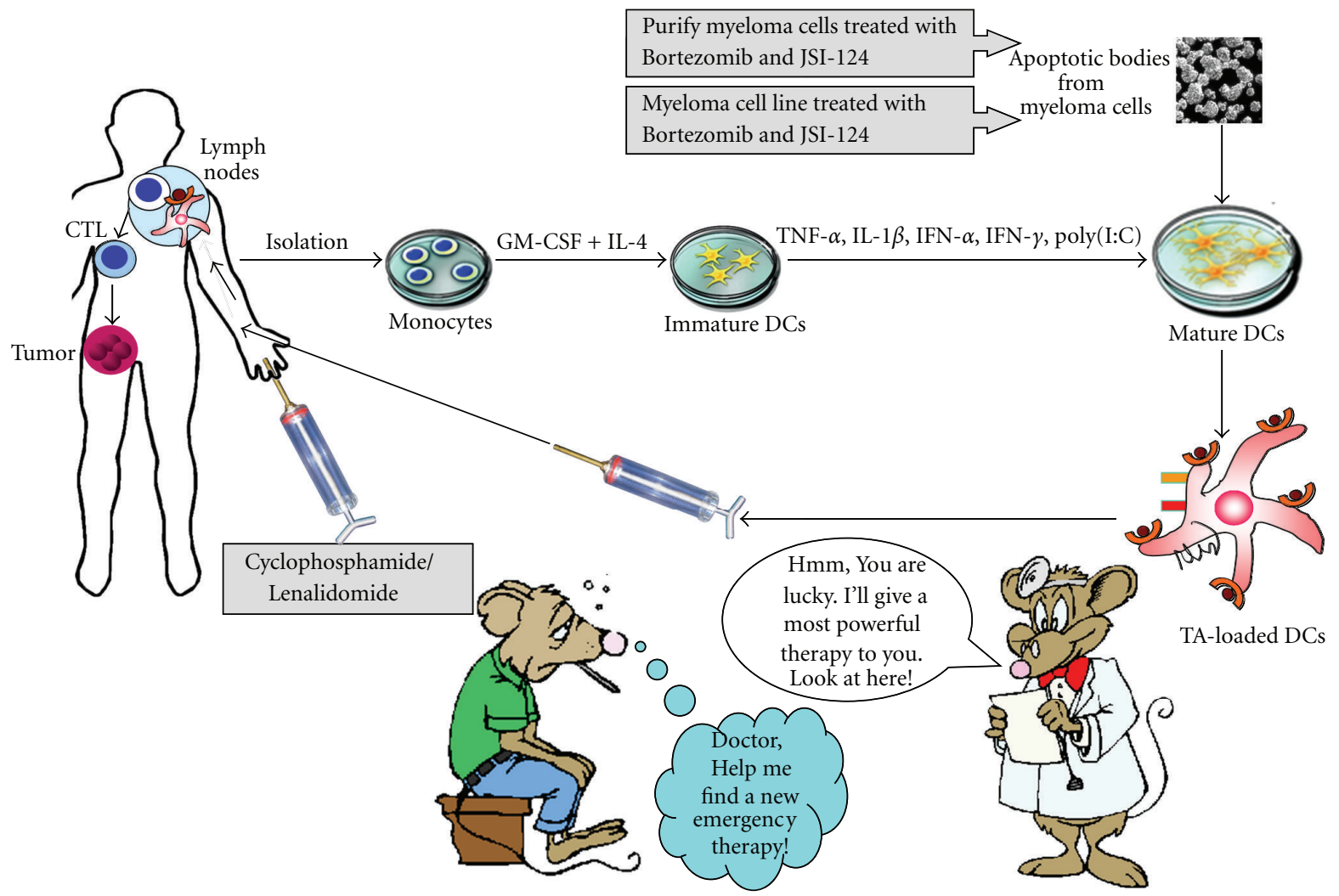

FIGURE 3: Generation of DC-based vaccines from patients with MM. Isolated monocytes from peripheral blood of patients are cultured with GM-CSF and IL-4 to produce immature DCs. Immature DCs were matured with $\alpha$-polarizing cytokines cocktail to generate $\alpha$-type 1-polarized DCs and were loaded with apoptotic bodies from myeloma cells or myeloma cell line which were induced in the presence of bortezomib and JSI-124. Tumor antigens-loaded DCs were then injected into patients in combination with either cyclophosphamide or lenalidomide to induce strong immune responses against the tumor.

therapy), or with adjuvant, will provide vigorous and maintained immune responses with the benefit clinical efficacy. The most promising DC-based vaccine in patients with MM was described in Figure 3.

\section{Conflict of Interests}

The authors have no relevant affiliations or financial involvement with any organization or entity with a financial interest in or financial conflict with the subject matter or materials discussed in the paper.

\section{Acknowledgments}

This study was financially supported by Grant no. 20110005285 from General Researcher Program Type II of the National Research Foundation of Korea; Grant no. RTI0501-01 from the Regional Technology Innovation Program of the Ministry of Commerce, Industry and Energy; Grant no. A000200058 from the Regional Industrial Technology Development Program of the Ministry of Knowledge and Economy; Grant no. 1120390 from the National R\&D Program for Cancer Control, Ministry for Health and Welfare; Grant no. 2011-0030034 from Leading Foreign Research Institute
Recruitment Program through the National Research Foundation of Korea (NRF) funded by the Ministry of Education, Science and Technology (MEST), Republic of Korea.

\section{References}

[1] R. A. Kyle and S. V. Rajkumar, "Multiple myeloma," The New England Journal of Medicine, vol. 351, no. 18, pp. 1860-1873, 2004.

[2] B. Sirohi and R. Powles, "Multiple myeloma," Lancet, vol. 363, no. 9412, pp. 875-887, 2004.

[3] M. Attal and J. L. Harousseau, "The role of high-dose therapy with autologous stem cell support in the era of novel agents," Seminars in Hematology, vol. 46, no. 2, pp. 127-132, 2009.

[4] S. Lonial and J. Cavenagh, "Emerging combination treatment strategies containing novel agents in newly diagnosed multiple myeloma," British Journal of Haematology, vol. 145, no. 6, pp. 681-708, 2009.

[5] J. A. Pérez-Simón, R. Martino, A. Alegre et al., "Chronic but not acute graft-versus-host disease improves outcome in multiple myeloma patients after non-myeloablative allogeneic transplantation," British Journal of Haematology, vol. 121, no. 1, pp. 104-108, 2003.

[6] S. J. Harrison and G. Cook, "Immunotherapy in multiple myeloma-possibility or probability?" British Journal of Haematology, vol. 130, no. 3, pp. 344-362, 2005. 
[7] S. J. Harrison, G. Cook, R. J. B. Nibbs, and H. M. Prince, "Immunotherapy of multiple myeloma: the start of a long and tortuous journey," Expert Review of Anticancer Therapy, vol. 6, no. 12, pp. 1769-1785, 2006.

[8] J. Banchereau and R. M. Steinman, "Dendritic cells and the control of immunity," Nature, vol. 392, no. 6673, pp. 245252, 1998.

[9] C. D. L. Reid, "Dendritic cells and immunotherapy for malignant disease," British Journal of Haematology, vol. 112, no. 4, pp. 874-887, 2001.

[10] D. Ridgway, "The first 1000 dendritic cell vaccinees," Cancer Investigation, vol. 21, no. 6, pp. 873-886, 2003.

[11] K. Palucka, H. Ueno, and J. Banchereau, "Recent developments in cancer vaccines," Journal of Immunology, vol. 186, no. 3, pp. 1325-1331, 2011.

[12] J. Banchereau and A. K. Palucka, "Dendritic cells as therapeutic vaccines against cancer," Nature Reviews Immunology, vol. 5, no. 4, pp. 296-306, 2005.

[13] C. G. Figdor, I. J. M. de Vries, W. J. Lesterhuis, and C. J. M. Melief, "Dendritic cell immunotherapy: mapping the way," Nature Medicine, vol. 10, no. 5, pp. 475-480, 2004.

[14] D. N. J. Hart and G. R. Hill, "Dendritic cell immunotherapy for cancer: application to low-grade lymphoma and multiple myeloma," Immunology and Cell Biology, vol. 77, no. 5, pp. 451-459, 1999.

[15] S. Bergenbrant, Q. Yi, A. Österborg et al., "Modulation of anti-idiotypic immune response by immunization with the autologous $\mathrm{M}$-component protein in multiple myeloma patients," British Journal of Haematology, vol. 92, no. 4, pp. 840846, 1996.

[16] L. W. Kwak, D. D. Taub, P. L. Duffey et al., "Transfer of myeloma idiotype-specific immunity from an actively immunised marrow donor," Lancet, vol. 345, no. 8956, pp. 1016-1020, 1995.

[17] Y. Li, M. Bendandi, Y. Deng et al., "Tumor-specific recognition of human myeloma cells by idiotype-induced CD8+ T cells," Blood, vol. 96, no. 8, pp. 2828-2833, 2000.

[18] Y. J. Wen, B. Barlogie, and Q. Yi, "Idiotype-specific cytotoxic $\mathrm{T}$ lymphocytes in multiple myeloma: evidence for their capacity to lyse autologous primary tumor cells," Blood, vol. 97, no. 6, pp. 1750-1755, 2001.

[19] A. W. Butch, K. A. Kelly, and N. C. Munshi, "Dendritic cells derived from multiple myeloma patients efficiently internalize different classes of myeloma protein," Experimental Hematology, vol. 29, no. 1, pp. 85-92, 2001.

[20] S. H. Lim and R. Bailey-Wood, "Idiotypic protein-pulsed dendritic cell vaccination in multiple myeloma," International Journal of Cancer, vol. 83, no. 2, pp. 215-222, 1999.

[21] A. Liso, K. E. Stockerl-Goldstein, S. Auffermann-Gretzinger et al., "Idiotype vaccination using dendritic cells after autologous peripheral blood progenitor cell transplantation for multiple myeloma," Biology of Blood and Marrow Transplantation, vol. 6, no. 6, pp. 621-627, 2000.

[22] S. Titzer, O. Christensen, O. Manzke et al., "Vaccination of multiple myeloma patients with idiotype-pulsed dendritic cells: immunological and clinical aspects," British Journal of Haematology, vol. 108, no. 4, pp. 805-816, 2000.

[23] Q. Yi, R. Desikan, B. Barlogie, and N. Munshi, "Optimizing dendritic cell-based immunotherapy in multiple myeloma," British Journal of Haematology, vol. 117, no. 2, pp. 297-305, 2002.

[24] V. L. Reichardt, C. Milazzo, W. Brugger, H. Einsele, L. Kanz, and P. Brossart, "Idiotype vaccination of multiple myeloma patients using monocyte-derived dendritic cells," Haematologica, vol. 88, no. 10, pp. 1139-1149, 2003.
[25] M. Bendandi, M. Rodríguez-Calvillo, S. Inogés et al., "Combined vaccination with idiotype-pulsed allogeneic dendritic cells and soluble protein idiotype for multiple myeloma patients relapsing after reduced-intensity conditioning allogeneic stem cell transplantation," Leukemia and Lymphoma, vol. 47, no. 1, pp. 29-37, 2006.

[26] Q. Yi, S. Szmania, J. Freeman et al., “Optimizing dendritic cell-based immunotherapy in multiple myeloma: intranodal injections of idiotype-pulsed CD40 ligand-matured vaccines led to induction of type-1 and cytotoxic T-cell immune responses in patients," British Journal of Haematology, vol. 150, no. 5, pp. 554-564, 2010.

[27] C. Röllig, C. Schmidt, M. Bornhäuser, G. Ehninger, M. Schmitz, and S. Auffermann-Gretzinger, "Induction of cellular immune responses in patients with stage-I multiple myeloma after vaccination with autologous idiotype-pulsed dendritic cells," Journal of Immunotherapy, vol. 34, no. 1, pp. 100-106, 2011.

[28] Y. J. Wen, M. Ling, R. Bailey-Wood, and S. H. Lim, "Idiotypic protein-pulsed adherent peripheral blood mononuclear cellderived dendritic cells prime immune system in multiple myeloma," Clinical Cancer Research, vol. 4, no. 4, pp. 957962, 1998.

[29] A. Österborg, Q. Yi, L. Henriksson et al., "Idiotype immunization combined with granulocyte-macrophage colonystimulating factor in myeloma patients induced type I, major histocompatibility complex-restricted, CD8- and CD4-specific T-cell responses," Blood, vol. 91, no. 7, pp. 2459-2466, 1998.

[30] R. B. Batchu, A. M. Moreno, S. M. Szmania et al., "Protein transduction of dendritic cells for NY-ESO-1-based immunotherapy of myeloma," Cancer Research, vol. 65, no. 21, pp. 10041-10049, 2005.

[31] P. Brossart, A. Schneider, P. Dill et al., "The epithelial tumor antigen MUC1 is expressed in hematological malignancies and is recognized by MUC1-specific cytotoxic T-lymphocytes," Cancer Research, vol. 61, no. 18, pp. 6846-6850, 2001.

[32] M. Hundemer, S. Schmidt, M. Condomines et al., "Identification of a new HLA-A2-restricted T-cell epitope within HM1.24 as immunotherapy target for multiple myeloma," Experimental Hematology, vol. 34, no. 4, pp. 486-496, 2006.

[33] S. H. Lim, Z. Wang, M. Chiriva-Internati, and Y. Xue, "Sperm protein 17 is a novel cancer-testis antigen in multiple myeloma," Blood, vol. 97, no. 5, pp. 1508-1510, 2001.

[34] J. Qian, J. Xie, S. Hong et al., "Dickkopf-1 (DKK1) is a widely expressed and potent tumor-associated antigen in multiple myeloma," Blood, vol. 110, no. 5, pp. 1587-1594, 2007.

[35] S. Szmania, G. Tricot, and F. van Rhee, "NY-ESO-1 immunotherapy for multiple myeloma," Leukemia and Lymphoma, vol. 47, no. 10, pp. 2037-2048, 2006.

[36] C. Milazzo, V. L. Reichardt, M. R. Müller, F. Grünebach, and P. Brossart, "Induction of myeloma-specific cytotoxic T cells using dendritic cells transfected with tumor-derived RNA," Blood, vol. 101, no. 3, pp. 977-982, 2003.

[37] F. Van Rhee, S. M. Szmania, F. Zhan et al., "NY-ESO1 is highly expressed in poor-prognosis multiple myeloma and induces spontaneous humoral and cellular immune responses," Blood, vol. 105, no. 10, pp. 3939-3944, 2005.

[38] M. Chiriva-lnternati, Z. Wang, E. Salati, K. Bumm, B. Barlogie, and S. H. Lim, "Sperm protein 17 (Sp17) is a suitable target for immunotherapy of multiple myeloma," Blood, vol. 100, no. 3, pp. 961-965, 2002. 
[39] M. Chiriva-Internati, Z. Wang, E. Salati, D. Wroblewski, and S. H. Lim, "Successful generation of sperm protein 17 (Sp17)-specific cytotoxic T lymphocytes from normal donors: implication for tumour-specific adoptive immunotherapy following allogeneic stem cell transplantation for Sp17positive multiple myeloma," Scandinavian Journal of Immunology, vol. 56, no. 4, pp. 429-433, 2002.

[40] R. H. Vonderheide, W. C. Hahn, J. L. Schultze, and L. M. Nadler, "The telomerase catalytic subunit is a widely expressed tumor-associated antigen recognized by cytotoxic $\mathrm{T}$ lymphocytes," Immunity, vol. 10, no. 6, pp. 673-679, 1999.

[41] D. Ocadlikova, F. Kryukov, K. Mollova et al., "Generation of myeloma-specific T cells using dendritic cells loaded with MUC1- and hTERT- drived nonapeptides or myeloma cell apoptotic bodies," Neoplasma, vol. 57, no. 5, pp. 455-464, 2010.

[42] T. Hayashi, T. Hideshima, M. Akiyama et al., "Ex vivo induction of multiple myeloma-specific cytotoxic T lymphocytes," Blood, vol. 102, no. 4, pp. 1435-1442, 2003.

[43] J. J. Lee, B. H. Choi, H. K. Kang et al., "Induction of multiple myeloma-specific cytotoxic $\mathrm{T}$ lymphocyte stimulation by dendritic cell pulsing with purified and optimized myeloma cell lysates," Leukemia and Lymphoma, vol. 48, no. 10, pp. 2022-2031, 2007.

[44] Y. J. Wen, R. Min, G. Tricot, B. Barlogie, and Q. Yi, “Tumor lysate-specific cytotoxic $\mathrm{T}$ lymphocytes in multiple myeloma: promising effector cells for immunotherapy," Blood, vol. 99, no. 9, pp. 3280-3285, 2002.

[45] T. N. Nguyen-Pham, C. M. Im, T. A. Thi Nguyen et al., "Induction of myeloma-specific cytotoxic $\mathrm{T}$ lymphocytes responses by natural killer cells stimulated-dendritic cells in patients with multiple myeloma," Leukemia Research, vol. 35, no. 9, pp. 1241-1247, 2011.

[46] D. H. Yang, M. H. Kim, C. Y. Hong et al., "Alpha-type 1polarized dendritic cells loaded with apoptotic allogeneic myeloma cell line induce strong CTL responses against autologous myeloma cells," Annals of Hematology, vol. 89, no. 8, pp. 795-801, 2010.

[47] J. Qian, S. Wang, J. Yang et al., “Targeting heat shock proteins for immunotherapy in multiple myeloma: generation of myeloma-specific CTLs using dendritic cells pulsed with tumor-derived gp96," Clinical Cancer Research, vol. 11, no. 24, pp. 8808-8815, 2005.

[48] J. Qian, S. Hong, S. Wang et al., "Myeloma cell line-derived, pooled heat shock proteins as a universal vaccine for immunotherapy of multiple myeloma," Blood, vol. 114, no. 18, pp. 3880-3889, 2009.

[49] J. Gong, S. Koido, D. Chen et al., "Immunization against murine multiple myeloma with fusions of dendritic and plasmacytoma cells is potentiated by interleukin 12," Blood, vol. 99, no. 7, pp. 2512-2517, 2002.

[50] S. Hao, X. Bi, S. Xu et al., "Enhanced antitumor immunity derived from a novel vaccine of fusion hybrid between dendritic and engineered myeloma cells," Experimental Oncology, vol. 26, no. 4, pp. 300-306, 2004.

[51] B. Vasir, V. Borges, Z. Wu et al., "Fusion of dendritic cells with multiple myeloma cells results in maturation and enhanced antigen presentation," British Journal of Haematology, vol. 129, no. 5, pp. 687-700, 2005.

[52] J. Rosenblatt, B. Vasir, L. Uhl et al., "Vaccination with dendritic cell/tumor fusion cells results in cellular and humoral antitumor immune responses in patients with multiple myeloma," Blood, vol. 117, no. 2, pp. 393-402, 2011.
[53] M. Q. Lacy, S. Mandrekar, A. Dispenzieri et al., "Idiotypepulsed antigen presenting cells following autologous transplantation for multiple myeloma may be associated with prolonged survival," American Journal of Hematology, vol. 84, no. 12, pp. 799-802, 2009.

[54] H. Quach, D. Ritchie, A. K. Stewart et al., "Mechanism of action of immunomodulatory drugs (IMiDS) in multiple myeloma," Leukemia, vol. 24, no. 1, pp. 22-32, 2010.

[55] R. D. Brown, B. Pope, A. Murray et al., "Dendritic cells from patients with myeloma are numerically normal but functionally defective as they fail to up-regulate CD80 (B7-1) expression after huCD40LT stimulation because of inhibition by transforming growth factor- $\beta 1$ and interleukin-10," Blood, vol. 98, no. 10, pp. 2992-2998, 2001.

[56] M. Ratta, F. Fagnoni, A. Curti et al., "Dendritic cells are functionally defective in multiple myeloma: the role of interleukin-6," Blood, vol. 100, no. 1, pp. 230-237, 2002.

[57] M. Tucci, S. Stucci, S. Strippoli, F. Dammacco, and F. Silvestris, "Dendritic cells and malignant plasma cells: an alliance in multiple myeloma tumor progression?" Oncologist, vol. 16, no. 7, pp. 1040-1048, 2011.

[58] J. Banchereau, F. Briere, C. Caux et al., "Immunobiology of dendritic cells," Annual Review of Immunology, vol. 18, pp. 767-811, 2000.

[59] W. Zou, "Immunosuppressive networks in the tumour environment and their therapeutic relevance," Nature Reviews Cancer, vol. 5, no. 4, pp. 263-274, 2005.

[60] H. Yu, M. Kortylewski, and D. Pardoll, "Crosstalk between cancer and immune cells: role of STAT3 in the tumour microenvironment," Nature Reviews Immunology, vol. 7, no. 1, pp. 41-51, 2007.

[61] M. Beyer, M. Kochanek, T. Giese et al., "In vivo peripheral expansion of naive $\mathrm{CD} 4+\mathrm{CD} 25$ high FoxP3+ regulatory $\mathrm{T}$ cells in patients with multiple myeloma," Blood, vol. 107, no. 10, pp. 3940-3949, 2006.

[62] M. K. Brimnes, A. J. Vangsted, L. M. Knudsen et al., "Increased level of both CD4+FOXP3+ Regulatory t Cells and CD14+HLA-DR-/low myeloid-derived suppressor cells and decreased level of dendritic cells in patients with multiple myeloma," Scandinavian Journal of Immunology, vol. 72, no. 6, pp. 540-547, 2010.

[63] S. Ostrand-Rosenberg and P. Sinha, "Myeloid-derived suppressor cells: linking inflammation and cancer," Journal of Immunology, vol. 182, no. 8, pp. 4499-4506, 2009.

[64] D. I. Gabrilovich and S. Nagaraj, "Myeloid-derived suppressor cells as regulators of the immune system," Nature Reviews Immunology, vol. 9, no. 3, pp. 162-174, 2009.

[65] F. J. Hsu, C. Benike, F. Fagnoni et al., "Vaccination of patients with B-cell lymphoma using autologous antigenpulsed dendritic cells," Nature Medicine, vol. 2, no. 1, pp. 52$58,1996$.

[66] H. Jonuleit, U. Kühn, G. Müller et al., "Pro-inflammatory cytokines and prostaglandins induce maturation of potent immunostimulatory dendritic cells under fetal calf serumfree conditions," European Journal of Immunology, vol. 27, no. 12, pp. 3135-3142, 1997.

[67] D. K. Banerjee, M. V. Dhodapkar, E. Matayeva, R. M. Steinman, and K. M. Dhodapkar, "Expansion of FOXP3high regulatory $\mathrm{T}$ cells by human dendritic cells (DCs) in vitro and after injection of cytokine-matured DCs in myeloma patients," Blood, vol. 108, no. 8, pp. 2655-2661, 2006.

[68] P. Kaliński, C. M. U. Hilkens, A. Snijders, F. G. M. Snijdewint, and M. L. Kapsenberg, "IL-12-deficient dendritic cells, generated in the presence of prostaglandin E2, promote type 
2 cytokine production in maturing human naive $\mathrm{T}$ helper cells," Journal of Immunology, vol. 159, no. 1, pp. 28-35, 1997.

[69] P. Kaliriski, P. L. Vieira, J. H. N. Schuitemaker, E. C. De Jong, and M. L. Kapsenberg, "Prostaglandin E2 is a selective inducer of interleukin-12 p40 (IL-12p40) production and an inhibitor of bioactive IL-12p70 heterodimer," Blood, vol. 97, no. 11, pp. 3466-3469, 2001.

[70] S. Yamazaki, K. Inaba, K. V. Tarbell, and R. M. Steinman, "Dendritic cells expand antigen-specific Foxp3+CD25 $+\mathrm{CD} 4+$ regulatory $\mathrm{T}$ cells including suppressors of alloreactivity," Immunological Reviews, vol. 212, pp. 314-329, 2006.

[71] R. B. Mailliard, A. Wankowicz-Kalinska, Q. Cai et al., " $\alpha$ type-1 polarized dendritic cells: a novel immunization tool with optimized CTL-inducing activity," Cancer Research, vol. 64, no. 17, pp. 5934-5937, 2004.

[72] J. J. Lee, K. A. Foon, R. B. Mailliard, R. Muthuswamy, and P. Kalinski, "Type 1-polarized dendritic cells loaded with autologous tumor are a potent immunogen against chronic lymphocytic leukemia," Journal of Leukocyte Biology, vol. 84, no. 1, pp. 319-325, 2008.

[73] T. Y. Jung, T. N. N. Pham, A. Umeyama et al., "Ursolic acid isolated from Uncaria rhynchophylla activates human dendritic cells via TLR2 and/or TLR4 and induces the production of IFN- $\gamma$ by CD4+ naïve T cells," European Journal of Pharmacology, vol. 643, no. 2-3, pp. 297-303, 2010.

[74] W. K. Bae, A. Umeyama, I. J. Chung, J. J. Lee, and M. Takei, "Uncarinic acid C plus IFN- $\gamma$ generates monocyte-derived dendritic cells and induces a potent Th1 polarization with capacity to migrate," Cellular Immunology, vol. 266, no. 1, pp. 104-110, 2010.

[75] S. Koido, E. Hara, S. Homma et al., "Dendritic cells fused with allogeneic colorectal cancer cell line present multiple colorectal cancer-specific antigens and induce antitumor immunity against autologous tumor cells," Clinical Cancer Research, vol. 11, no. 21, pp. 7891-7900, 2005.

[76] A. K. Palucka, H. Ueno, J. Connolly et al., "Dendritic cells loaded with killed allogeneic melanoma cells can induce objective clinical responses and MART-1 specific CD8+ Tcell immunity," Journal of Immunotherapy, vol. 29, no. 5, pp. 545-557, 2006.

[77] D. H. Yang, M. H. Kim, Y. K. Lee et al., "Successful cross-presentation of allogeneic myeloma cells by autologous alpha-type 1-polarized dendritic cells as an effective tumor antigen in myeloma patients with matched monoclonal immunoglobulins," Annals of Hematology, vol. 90, no. 12, pp. 1419-1426, 2011.

[78] J. Savill, I. Dransfield, C. Gregory, and C. Haslett, "A blast from the past: clearance of apoptotic cells regulates immune responses," Nature Reviews Immunology, vol. 2, no. 12, pp. 965-975, 2002.

[79] H. Kitamura, H. Kamon, S. I. Sawa et al., "IL-6-STAT3 controls intracellular MHC class II $\alpha \beta$ dimer level through cathepsin $S$ activity in dendritic cells," Immunity, vol. 23, no. 5, pp. 491-502, 2005.

[80] Y. Nefedova, S. Nagaraj, A. Rosenbauer, C. Muro-Cacho, S. M. Sebti, and D. I. Gabrilovich, "Regulation of dendritic cell differentiation and antitumor immune response in cancer by pharmacologic-selective inhibition of the Janus-activated kinase 2/signal transducers and activators of transcription 3 pathway," Cancer Research, vol. 65, no. 20, pp. 9525-9535, 2005.

[81] Y. Nefedova and D. I. Gabrilovich, "Targeting of Jak/STAT pathway in antigen presenting cells in cancer," Current Cancer Drug Targets, vol. 7, no. 1, pp. 71-77, 2007.
[82] M. Kortylewski, R. Jove, and H. Yu, "Targeting STAT3 affects melanoma on multiple fronts," Cancer and Metastasis Reviews, vol. 24, no. 2, pp. 315-327, 2005.

[83] S. Wang, S. Hong, J. Yang et al., "Optimizing immunotherapy in multiple myeloma: restoring the function of patients' monocyte-derived dendritic cells by inhibiting p38 or activating MEK/ERK MAPK and neutralizing interleukin-6 in progenitor cells," Blood, vol. 108, no. 13, pp. 4071-4077, 2006.

[84] D. H. Yang, J. S. Park, C. J. Jin et al., "The dysfunction and abnormal signaling pathway of dendritic cells loaded by tumor antigen can be overcome by neutralizing VEGF in multiple myeloma," Leukemia Research, vol. 33, no. 5, pp. 665670, 2009.

[85] G. Ferlazzo, M. L. Tsang, L. Moretta, G. Melioli, R. M. Steinman, and C. Münz, "Human dendritic cells activate resting natural killer (NK) cells and are recognized via the NKp30 receptor by activated NK cells," Journal of Experimental Medicine, vol. 195, no. 3, pp. 343-351, 2002.

[86] F. Gerosa, B. Baldani-Guerra, C. Nisii, V. Marchesini, G. Carra, and G. Trinchieri, "Reciprocal activating interaction between natural killer cells and dendritic cells," Journal of Experimental Medicine, vol. 195, no. 3, pp. 327-333, 2002.

[87] D. Piccioli, S. Sbrana, E. Melandri, and N. M. Valiante, "Contact-dependent stimulation and inhibition of dendritic cells by natural killer cells," Journal of Experimental Medicine, vol. 195, no. 3, pp. 335-341, 2002.

[88] R. B. Mailliard, Y. I. Son, R. Redlinger et al., "Dendritic cells mediate NK cell help for Th1 and CTL responses: two-signal requirement for the induction of NK cell helper function," Journal of Immunology, vol. 171, no. 5, pp. 2366-2373, 2003.

[89] T. N. N. Pham, C. Y. Hong, J. J. Min et al., "Enhancement of antitumor effect using dendritic cells activated with natural killer cells in the presence of Toll-like receptor agonist," Experimental and Molecular Medicine, vol. 42, no. 6, pp. 407419, 2010.

[90] R. Kim, M. Emi, and K. Tanabe, "Cancer immunoediting from immune surveillance to immune escape," Immunology, vol. 121, no. 1, pp. 1-14, 2007.

[91] R. H. Prabhala, P. Neri, J. E. Bae et al., "Dysfunctional T regulatory cells in multiple myeloma," Blood, vol. 107, no. 1, pp. 301-304, 2006.

[92] T. J. Curiel, "Tregs and rethinking cancer immunotherapy," Journal of Clinical Investigation, vol. 117, no. 5, pp. 11671174, 2007.

[93] R. Muthuswamy, J. Urban, J. J. Lee, T. A. Reinhart, D. Bartlett, and P. Kalinski, "Ability of mature dendritic cells to interact with regulatory T cells is imprinted during maturation," Cancer Research, vol. 68, no. 14, pp. 5972-5978, 2008.

[94] M. A. Mihalyo, A. D. H. Doody, J. P. McAleer et al., "In vivo cyclophosphamide and IL-2 treatment impedes selfantigen-induced effector CD4 cell tolerization: implications for adoptive immunotherapy," Journal of Immunology, vol. 172, no. 9, pp. 5338-5345, 2004.

[95] J. Y. Liu, Y. Wu, X. S. Zhang et al., "Single administration of low dose cyclophosphamide augments the antitumor effect of dendritic cell vaccine," Cancer Immunology, Immunotherapy, vol. 56, no. 10, pp. 1597-1604, 2007.

[96] L. Höltl, R. Ramoner, C. Zelle-Rieser et al., "Allogeneic dendritic cell vaccination against metastatic renal cell carcinoma with or without cyclophosphamide," Cancer Immunology, Immunotherapy, vol. 54, no. 7, pp. 663-670, 2005. 
[97] G. Faure-André, P. Vargas, M. I. Yuseff et al., "Regulation of dendritic cell migration by CD74, the MHC class II-associated invariant chain," Science, vol. 322, no. 5908, pp. 17051710, 2008.

[98] L. Frasca, G. Fedele, S. Deaglio et al., “CD38 orchestrates migration, survival, and Th1 immune response of human mature dendritic cells," Blood, vol. 107, no. 6, pp. 2392-2399, 2006.

[99] T. N. Nguyen-Pham, M. S. Lim, T. A.T. Nguyen et al., "Type $i$ and II interferons enhance dendritic cell maturation and migration capacity by regulating CD38 and CD74 that have synergistic effects with TLR agonists," Cellular and Molecular Immunology, vol. 8, no. 4, pp. 341-347, 2011.

[100] S. K. Kumar, S. V. Rajkumar, A. Dispenzieri et al., "Improved survival in multiple myeloma and the impact of novel therapies," Blood, vol. 111, no. 5, pp. 2516-2520, 2008.

[101] A. K. Stewart, P. L. Bergsagel, P. R. Greipp et al., "A practical guide to defining high-risk myeloma for clinical trials, patient counseling and choice of therapy," Leukemia, vol. 21, no. 3, pp. 529-534, 2007.

[102] A. P. Rapoport, E. A. Stadtmauer, N. Aqui et al., "Restoration of immunity in lymphopenic individuals with cancer by vaccination and adoptive T-cell transfer," Nature Medicine, vol. 11, no. 11, pp. 1230-1237, 2005.

[103] E. Alici, K. V. Konstantinidis, T. Sutlu et al., "Anti-myeloma activity of endogenous and adoptively transferred activated natural killer cells in experimental multiple myeloma model," Experimental Hematology, vol. 35, no. 12, pp. 1839-1846, 2007. 


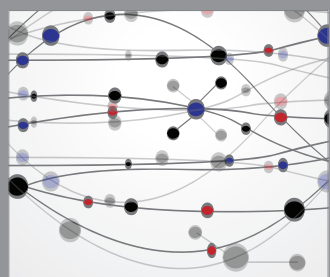

The Scientific World Journal
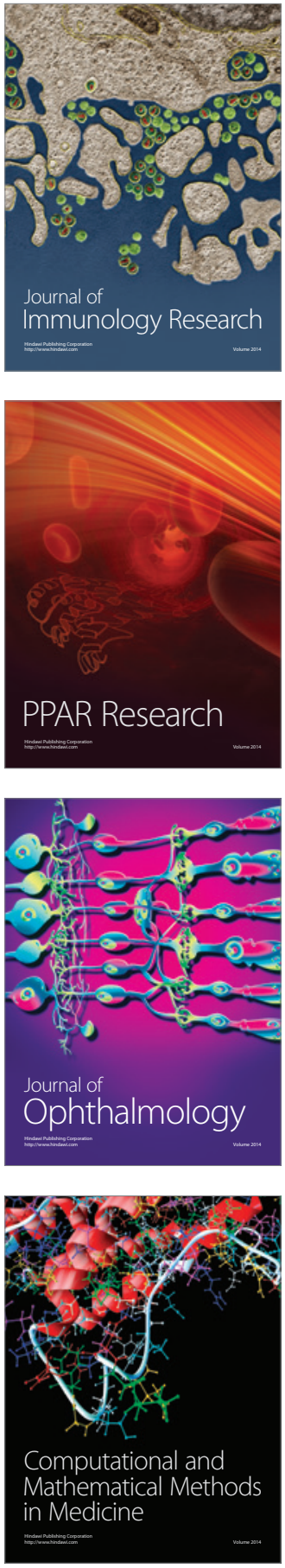

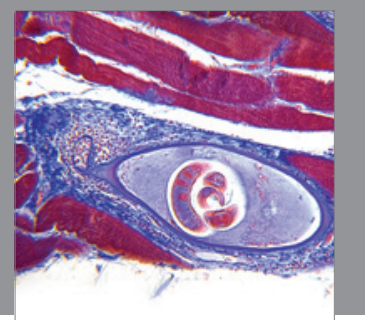

Gastroenterology

Research and Practice
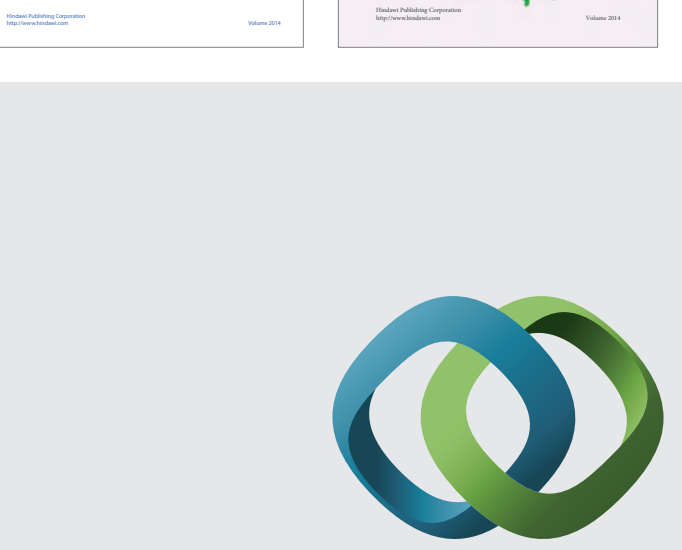

\section{Hindawi}

Submit your manuscripts at

http://www.hindawi.com
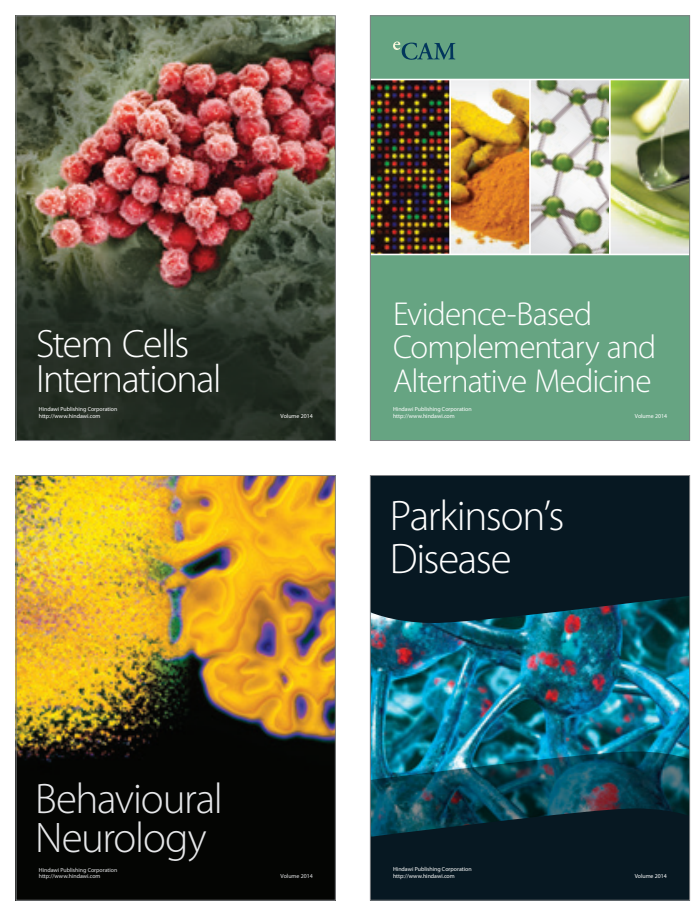

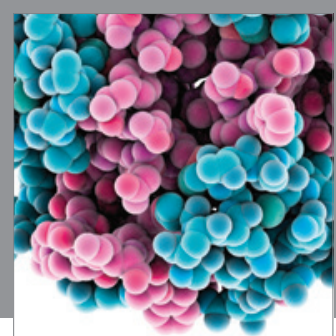

Journal of
Diabetes Research

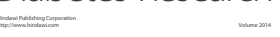

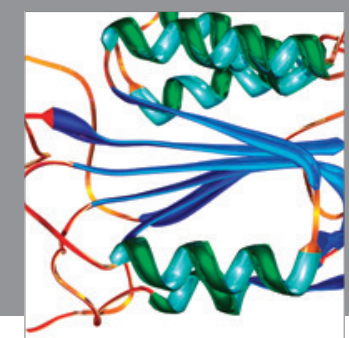

Disease Markers
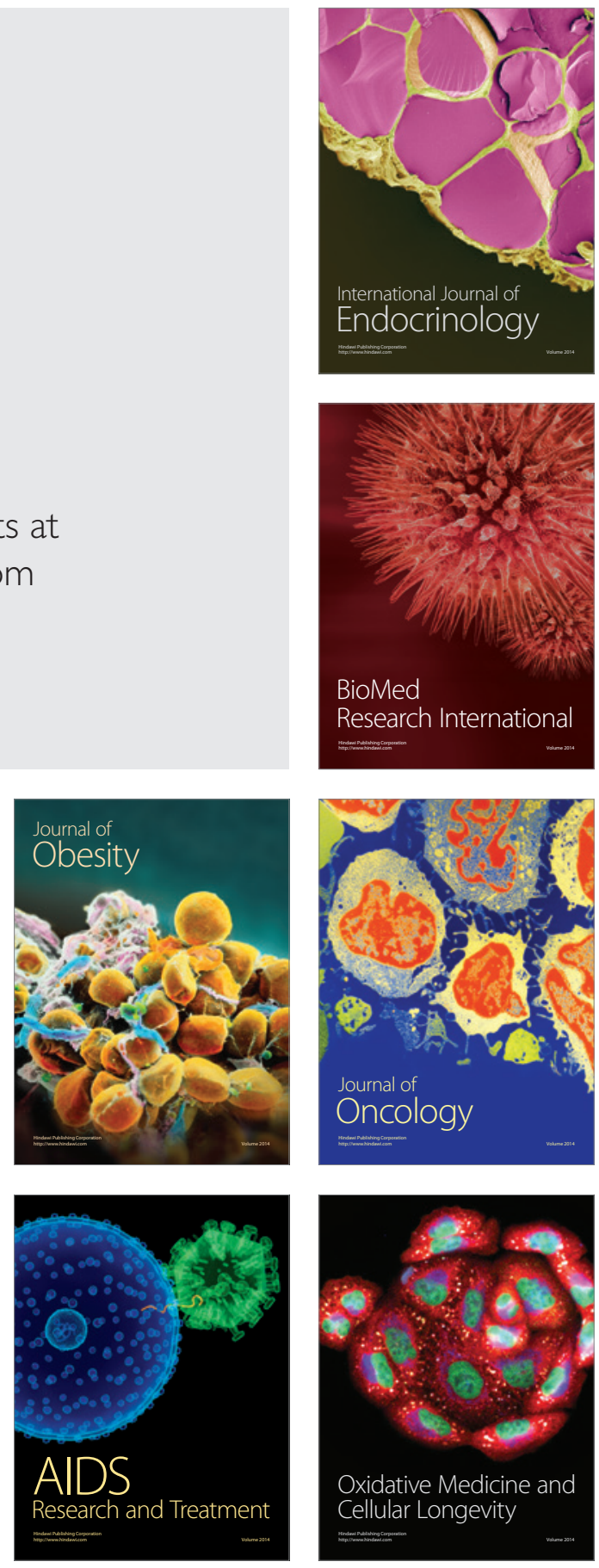